\title{
Percepção de alunos com paralisia cerebral sobre o uso de RECURSOS DE TECNOLOGIA ASSISTIVA NA ESCOLA REGULAR ${ }^{1}$ PERCEPTION OF STUDENTS WITH CEREBRAL PALSY ABOUT THE USE OF ASSISTIVE TECHNOLOGY RESOURCES IN MAINSTREAM SCHOOLS
}

\author{
Ana Cristina de Jesus ALVES² \\ Thelma Simões MATSUKURA ${ }^{3}$
}

RESUMO: o Censo Escolar realizado no Brasil em 2006 localizou aproximadamente 29.000 alunos deficientes físicos matriculados em classes comuns. A escolarização da criança com comprometimento motor na escola comum tem sido discutida juntamente com as possíveis estratégias que possam colaborar para a participação e aprendizagem desse aluno. Uma das estratégias indicadas tem sido o uso de recursos de tecnologia assistiva para favorecer a execução das tarefas pedagógicas, porém pouco se sabe sobre a implementação, a eficácia ou as contribuições desses recursos no processo de escolarização da criança com deficiência física. O objetivo desta pesquisa foi identificar, a partir do ponto de vista do aluno com paralisia cerebral, as contribuições, dificuldades e o cotidiano implicado no uso de recursos de tecnologia assitiva no contexto da escolarização no ensino regular. Participaram deste estudo cinco alunos com diagnóstico de paralisia cerebral nível motor IV e V segundo o Sistema de Classificação da Função Motora Grossa para paralisia cerebral - GMFCS. Foi utilizado um roteiro de entrevista semiestruturado com as crianças e os dados obtidos foram transcritos e analisados na íntegra, optando-se em realizar uma categorização de acordo com os temas da entrevista. As percepções das crianças foram relevantes e elas mostraram-se capazes de apontar demandas e identificar quando e como os recursos podem ser limitantes dentro do contexto. Assim, considerar as opiniões e a participação da criança na identificação de recursos de tecnologia pode contribuir na compreensão do impacto, das demandas e das possíveis contribuições no processo de implementação e utilização do recurso de tecnologia assistiva.

PALAVRAS-CHAVE: Tecnologia. Educação Especial. Aluno com Deficiência. Deficiências Físicas.

ABSTRACT: The Brazilian 2006 School Census identified about 29,000 students with physical disability enrolled in regular classes. Schooling of children with motor impairments in regular schools has been under discussion in order to uncover possible strategies that could contribute to student participation and learning. One of the recommended strategies is the use of assistive technology resources to facilitate implementation of pedagogical tasks, but little is known about implementation, effectiveness or contributions of these resources in the educational process of children with disabilities. The aim of this study was to identify, from the cerebral palsy students' standpoint, the daily contributions and difficulties involved in using assistive technology resources in the schooling context. The study included five students with cerebral palsy motor level IV and V according to Gross Motor Function Classification System for Cerebral Palsy - GMFCS. An interview guide was used with children and the data were transcribed and analyzed; the categorization was established according to themes that emerged during the interviews. Children's perceptions were relevant; they were able to identify requirements, and when and how resources can be limiting in context. Thus, considering children's opinions and participation in technological resources identification can contribute to understanding the impact, demands and possible contributions to implementation processes and use of assistive technology resources.

KEYWORDS: Technology. Special Education. Students with Disabilities. Physical Disabilities

\footnotetext{
${ }^{1}$ Este estudo recebeu apoio financeiro da CAPES

${ }^{2}$ Terapeuta Ocupacional Doutoranda pela Universidade Federal de São Carlos - Centro de Educação e Ciências Humanas - Programa de Pós-Graduação em Educação Especial. crisjalves@yahoo.com.br

${ }^{3}$ Terapeuta Ocupacional, Doutora pela Universidade de São Paulo - Programa de Pós Graduação em Saúde Mental. Universidade Federal de São Carlos - Centro de Ciências Biológicas e da Saúde. Programa de PósGraduação em Educação Especial. Programa de Pós-Graduação em Terapia Ocupacional. thelma@ufscar.br
} 


\section{INTRODUÇÃo}

O período escolar é caracterizado como uma importante fase para o desempenho ocupacional da criança, pois o ingresso à escola faz com que esta seja reconhecida pela sua capacidade de realizar tarefas valorizadas em seu meio.

Além disso, na fase escolar, não só o contexto físico e social se alarga e diferencia, mas também as expectativas do meio social se tornam mais exigentes, a dependência é menos tolerada, as regras implícitas de convivência ficam mais complexas e o suporte está menos disponível. A exposição ao julgamento é mais evidente e instiga a criança a corresponder às expectativas da família, do professor e dos companheiros (MARTURANO, 2004).

O Censo Escolar realizado no Brasil no ano de 2010 localizou aproximadamente 308.112 alunos com necessidades educacionais especiais incluídos em classes comuns do ensino fundamental no Brasil (BRASIL, 2011). O Censo escolar de 2006 mostrou que o número de deficientes físicos matriculados foi de aproximadamente 29.000 (BRASIL, 2006).

Segundo Browning (2002), a deficiência física mais comumente encontrada é a paralisia cerebral e $50 \%$ das crianças que apresentam esse diagnóstico, com inteligência média ou alta, vivenciavam dificuldades no processo de alfabetização.

A paralisia cerebral foi definida por Gianni (2003) como um grupo de distúrbios motores não progressivo secundário à lesão do cérebro em desenvolvimento e, segundo Rotta (2002), surgem no Brasil 17.000 novos casos ao ano.

A paralisia cerebral pode ser classificada em cinco níveis motores funcionais com base no movimento voluntário da criança, especialmente andar e sentar, segundo o Sistema de Classificação da Função Motora Grossa para paralisia cerebral - GMFCS (PALISANO et al., 1997) ${ }^{4}$.

A classificação depende da idade da criança e a diferença entre os níveis de classificação proposta pelo GMFCS é permeada pelas limitações funcionais, pela necessidade de Tecnologia Assistiva para mobilidade e, em uma extensão menor, pela qualidade do movimento.

Os níveis diferenciam-se pelas limitações funcionais gradativas entre os níveis I, II, III, IV e V. Assim, pode-se descrever que as crianças do nível motor I, na faixa etária de 6 a 12 anos, são crianças que andam nos espaços internos e externos, sobem escadas sem limitações e possuem habilidades motoras grossas, incluindo correr e pular, mas a velocidade, o equilíbrio e a coordenação são reduzidos. Já no nível $\mathrm{V}$, todas as áreas de função motora estão limitadas. A distinção entre os níveis IV e $\mathrm{V}$ é que as crianças do nível $\mathrm{V}$ não têm independência nem mesmo no controle de posturas antigravitacionais básicas. A autolocomoção é alcançada

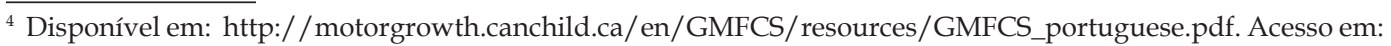
jun. 2011. 
somente se a criança puder aprender como operar uma cadeira de rodas motorizada (PALISANO et al., 1997).

\subsection{A CRIANÇA COM PARALISIA CEREBRAL E SEU DESEMPENHO NA ESCOLA}

Beckung e Hagberg (2002) apresentaram um estudo sobre as limitações funcionais de 176 crianças com paralisia cerebral em relação à mobilidade, educação e relações sociais. No estudo, as crianças de nível motor I e II segundo o GMFCS e o Sistema de Graduação da Função Bimanual Fina -BFMF (KRÄGELOH-MANN et al.,1993) não apresentaram limitações ou apresentaram limitações leves para frequentar a escola comum. Já as crianças do nível motor III apresentaram restrições moderadas a severas, e as crianças do nível IV e $\mathrm{V}$ tiveram limitação severa ou completa nas relações sociais e necessitaram de suporte pessoal ou ajustes especiais para frequentarem a escola comum (BECKUNG; HAGBERG, 2002).

Silva et al. (2004) avaliaram o tipo de comprometimento motor de 29 crianças com paralisia cerebral e o nível de participação de atividades funcionais em seis ambientes da escola regular (sala, banheiro, recreio, transporte, transições e lanche). Os resultados apontaram que o desempenho funcional das crianças com paralisia cerebral encontra-se bastante diferenciado em relação à turma em que estavam inseridas, apresentando restrições quanto ao uso dos materiais e áreas dos ambientes pesquisados. Na análise por nível de comprometimento motor, o estudo indicou que quanto maior a gravidade motora mais limitada é a participação, ou seja, o grupo de crianças que faz uso de cadeiras de rodas alcançou no máximo a metade da pontuação no School Function Assesment - SFA (COSTER et al., 1998). Essas limitações foram justificadas por duas variáveis: a autonomia na locomoção e a acessibilidade. As autoras discutem que apenas fazer o uso de cadeira de rodas não garante autonomia na locomoção se o direito de acessibilidade não for efetivado. Foi observado heterogeneidade de condições físicas das escolas, onde umas incluem modificações ambientais e outras com completa ausência de modificações. O estudo concluiu que o grau de comprometimento motor demonstrou ser um indicativo para o nível de participação, embora não seja plenamente esclarecedor quanto à funcionalidade da criança.

O estudo de Ostensjo, Carlberg e Vollestad (2005) descreveu a relação no uso de dispositivos assistivos e seu impacto em atividades diárias e no cuidado de crianças com paralisia cerebral. Foram estudadas 95 crianças classificadas em diferentes níveis motores segundo o GMFCS. Foram encontradas 1497 modificações, destas $80 \%$ pertenciam às crianças dos níveis motores IV e V. Os autores concluíram que os diferentes tipos de modificações beneficiam frequentemente as demandas funcionais de independência e de cuidado, principalmente das crianças de nível motor IV e V.

Estes estudos puderam mostrar que, embora haja maiores limitações funcionais para as crianças com paralisia cerebral de nível motor IV e V, o uso de 
recursos de Tecnologia Assistiva pode trazer benefícios em relação à diminuição da necessidade de auxílio e de cuidado.

\title{
1.2 A tecnologia assistiva no contexto escolar
}

O conceito de Tecnologia Assistiva no Brasil, de acordo com o Comitê de Ajudas Técnicas - Secretaria Especial dos Direitos Humanos da Presidência da República, diz respeito a

\begin{abstract}
[...] produtos, recursos, metodologias, estratégias, práticas e serviços que objetivam promover a funcionalidade, relacionada à atividade e participação, de pessoas com deficiência, incapacidades ou mobilidade reduzida, visando sua autonomia, independência, qualidade de vida e inclusão social. (BRASIL, 2007).
\end{abstract}

No âmbito internacional, as pesquisas envolvendo o tema Tecnologia Assistiva têm permeado algumas linhas de investigação como: estudos sobre os modelos teóricos para a implementação dos recursos e sistematização de avaliações, fatores que influenciam o uso bem sucedido dos recursos de Tecnologia Assistiva, estudos sobre as causas de abandono dos recursos de Tecnologia Assistiva e estudos de eficácia (SCHERER et al., 2005; COPLEY; ZIVIANI, 2004; LOVARINI; MCCLUSKEY; CURTIN, 2006).

Scherer et al. (2005) propõem o modelo Matching Person and Technology (MPT), o qual sugere que três áreas devam ser dirigidas ao avaliar a predisposição de um indivíduo ao uso da tecnologia: a) os fatores psicossociais do usuário como a motivação, a cooperação, o otimismo, a paciência, a autodisciplina, experiências positivas de vida, habilidades para o uso e a percepção entre a situação desejada e atual; b) os fatores do ambiente em que o recurso de Tecnologia Assistiva será utilizado, incluindo o apoio da família, dos pares, do empregador, o ajuste que recompense o uso do dispositivo e a exigência externa e c) os fatores específicos do recurso de tecnologia como a habilidade de ser usada sem desconforto ou stress, a compatibilidade com outras tecnologias, o custo, a credibilidade do recurso, a facilidade de uso no período presente e futuro e a portabilidade (SCHERER et al., 2005).

Em relação aos fatores que influenciam o uso bem sucedido de recursos de tecnologia na escola, Copley e Ziviani (2004) buscaram identificar, por meio de revisão de literatura, as barreiras encontradas para a integração da Tecnologia Assistiva. As barreiras encontradas na escola foram: a falta do treinamento e apoio apropriados da equipe de funcionários, atitudes negativas desses profissionais, processo inadequado de avaliação e do planejamento para o uso do recurso, financiamento insuficiente e dificuldades de obtenção e controle do equipamento.

Em relação aos estudos de eficácia, Lovarini, McCluskey e Curtin (2006) realizaram um estudo de revisão referente ao período de 2000 a 2005 utilizando os bancos de dados OTseeker, CINAHL, PubMed e Cochrane e apresentaram 19 estudos que abordavam a eficácia da Tecnologia Assistiva. Desses, foram encontradas experimentações controladas randomizadas $(n=8)$, estudos 
qualitativos $(n=6)$, revisões sistemáticas $(n=2)$, estudos de pré e pós-teste $(n=1)$ e revisões da literatura $(n=2)$. Os autores concluíram que parece haver uma falta geral dos estudos de alta qualidade que avaliem a eficácia trazida pelos equipamentos e dispositivos assistivos e indicaram que a falta da pesquisa por terapeutas ocupacionais e por outros profissionais é surpreendente, dado o custo e a frequência com que tal equipamento é prescrito.

Na literatura nacional encontram-se várias publicações sobre indicações de recursos às crianças com paralisia cerebral que visam favorecer o desempenho escolar.

Em publicações distribuídas pelo MEC, o uso de recursos de Comunicação Alternativa, de materiais e atividades adaptadas, de recursos de adequação postural, computador e o planejamento arquitetônico são apontados como facilitadores ao processo de aprendizagem do aluno com deficiência física e contribuintes ao profissional de educação na busca de soluções para minimizar limitações funcionais, motoras e sensoriais do aluno com deficiência física. (GODÓI; GALASSO; MIOSSO, 2002; SILVA; CASTRO; BRANCO, 2006; SCHINEMER et al., 2007; BRASIL, 2002; MANZINI; DELIBERATO, 2006; BERSCH; PELOSI, 2007).

Alpino (2003) em seu estudo sobre o processo de inclusão escolar discutiu sobre a necessidade de recursos adaptados nas escolas e apontou o uso de recursos de Tecnologia Assistiva como favoráveis ao processo de inclusão da criança com deficiência física.

Pode-se observar através desses estudos que, ainda que estas publicações apresentem sugestões de recursos possíveis ao contexto da inclusão escolar, poucos são os estudos encontrados quando utilizados os descritores equipamentos de auto-ajuda e deficiência nas bases de dados Medline, Lilacs e Sciello no período de 2000 a 2010, sobre a implementação, a eficácia ou as contribuições desses recursos no processo de escolarização da criança com deficiência física.

Os estudos aqui apresentados remetem à discussão sobre a escolarização da criança com maior comprometimento motor na escola comum, se a presença de recursos de Tecnologia Assistiva contribui realmente para a prática da inclusão escolar e a necessidade de se considerar o contexto e as percepções das pessoas que participam desse processo.

Os estudos internacionais já sugerem a importância da participação ativa das crianças em pesquisas que investiguem a repercussão trazida pelos recursos de Tecnologia Assistiva e mostram que, as percepções das crianças podem ser diferentes dos adultos devido à diferente fase do desenvolvimento, às suas experiências pessoais e ao que julgam prioridade (HUANG; SUGDEN; BEVERIDGE, 2009; HEMMINGSSON; LIDSTROM; NYGARD, 2009).

Portanto, o objetivo desta pesquisa foi identificar, a partir do ponto de vista do aluno com paralisia cerebral, as contribuições, dificuldades e o cotidiano implicado no uso de recursos de Tecnologia Assistiva no contexto da escolarização no ensino regular. 
Considera-se que a percepção do próprio aluno a respeito do uso do recurso de Tecnologia Assistiva pode trazer informações importantes e complementares em relação à forma que os recursos de Tecnologia Assistiva estão sendo implementados e utilizados no contexto escolar.

Este estudo faz parte da pesquisa intitulada: "A tecnologia assistiva como recurso à inclusão escolar de crianças com paralisia cerebral", a qual buscou investigar os efeitos do uso da Tecnologia Assistiva no contexto da escolarização do aluno com paralisia cerebral a partir de sua própria percepção, da percepção de seu professor e de seu cuidador.

\section{MÉtodo}

\subsection{Participantes}

Participaram deste estudo cinco alunos com diagnóstico de paralisia cerebral. Destes, dois alunos foram classificados com o nível motor IV (C1 e C2) e três com o nível motor V (C3, C4 e C5), segundo o GMFCS. A idade dos alunos variou de oito a 12 anos de idade e estes frequentavam do $3^{\circ}$ ao $5^{\circ}$ ano do ensino fundamental regular.

Como critério de inclusão dos participantes, foram considerados alunos matriculados na escola regular, com diagnóstico de paralisia cerebral que faziam uso, há pelo menos seis meses, de recurso de Tecnologia Assistiva na execução de tarefas de escrita e/ou comunicação.

Outro critério de inclusão dos participantes foi o nível de cognição das crianças avaliado pelos professores, a partir da necessidade de compreensão dos itens abordados na entrevista. Para isso, foi apresentado aos professores o roteiro de entrevista destinado às crianças para que os mesmos indicassem, segundo seu julgamento, o potencial cognitivo do aluno em responder a entrevista.

Foram considerados todos os recursos de Tecnologia Assistiva conceituados pelo Comitê de Ajudas Técnicas (BRASIL, 2007) e pelo decreto $n^{\circ}$ 3.298 de 20 de dezembro de $1999^{5}$. Dentre esses, os recursos de Tecnologia Assistiva utilizados pelas crianças foram: lápis engrossado, tarefas adaptadas, cadeiras de rodas, mesa adaptada, tarefa xerocada, escriba, pulseira de chumbo, molde vazado, tesoura adaptada, letras móveis e tabuleiro e prancha de comunicação. O tempo de uso dos recursos de Tecnologia Assistiva variou de oito meses a três anos.

\subsection{LOCAL}

A pesquisa foi realizada em escolas municipais localizadas em duas cidades do interior do Estado de São Paulo. A coleta de dados foi realizada na escola de vínculo das crianças e/ou na residência das mesmas, conforme opção da família.

5 Disponível em: http://legislacao.planalto.gov.br/legisla/legislacao.nsf/Viw_Identificacao/DEC\%20 3.298-1999?OpenDocument. Acesso em: jun. 2011. 


\subsection{INSTRUMENTOS}

Foi utilizado para a seleção dos participantes o Sistema de Classificação da Função Motora Grossa - GMFCS, versão adaptada para o português por Hiratuka e Matsukura (2007). O objetivo do uso do instrumento foi determinar o nível de habilidades motoras grossas presentes na criança e as suas limitações de acordo com sua faixa etária.

Um roteiro de entrevista semiestruturado, elaborado pela pesquisadora, foi utilizado para o aluno, que buscou focalizar a percepção do aluno sobre o recurso de Tecnologia Assistiva utilizado em sala de aula dividido em quatro temas: a) Tecnologia Assistiva (investiga características do recurso como facilidade de uso, dificuldades, forma de prescrição, orientações recebidas, participação na escolha e etc.); b) Tarefas de sala de aula (como é feita a tarefa, contribuições e dificuldades que o recurso oferece e outros); c) Socialização (interação do aluno, como se comunica, estratégias utilizadas para a comunicação) e d) Inclusão escolar (contribuições e dificuldades trazidas pelo recursos de Tecnologia Assistiva para a escolarização da criança na escola comum e como a inclusão escolar é percebida).

\subsection{Materiais}

Foi utilizado um gravador de áudio, uma filmadora, suporte para filmadora, prancha de Comunicação Alternativa temática, símbolos do Picture Comunication Symbols - PCS ${ }^{6}$, alfabeto impresso, bloco de notas e caneta.

\subsection{Procedimentos}

O projeto foi submetido e aprovado pelo Comitê de Ética em Pesquisa com Seres Humanos da Universidade Federal de São Carlos ${ }^{7}$. Também foi solicitada às Secretárias de Educação Especial de cada município, a autorização para realização da pesquisa nas escolas regulares. Ao ser aprovado, foram agendados encontros com a equipe da Secretaria de Educação Especial para o esclarecimento da proposta de trabalho e levantamento dos possíveis participantes. Estabelecidas as crianças alvo do estudo, os responsáveis pelos alunos, após conhecerem os objetivos do estudo, foram convidados a assinarem o termo de consentimento livre e esclarecido. Em seguida, foram agendados os encontros para o início da coleta de dados.

Neste estudo, observou-se a necessidade de suporte escolar da equipe de reabilitação a dois alunos. Realizou-se, portanto uma reunião com a equipe das escolas e com as cuidadoras para a viabilização dessa intervenção.

\footnotetext{
${ }^{6}$ Picture Comunication Symbols - PCS: sistema de comunicação criado em 1981 pela fonoaudióloga americana Roxanna Mayer Johnson. Foram originalmente desenhados para criar recursos pictográficos de comunicação consistentes, de forma rápida e economicamente viável. Disponível em http://www.clik.com.br/mj_01. html\#pcs. Acesso em: jul. 2010.

7 Comitê de Ética em Pesquisa com Seres Humanos da Universidade Federal de São Carlos CAAE 0094.0.135.00007 Parecer n $n^{\circ}: 279 / 2007$ 


\subsubsection{ColeTA DE DADOS}

Nas entrevistas com as crianças, o recurso do gravador de áudio foi utilizado para duas delas que tinham maior inteligibilidade na fala. Para as outras três, que apresentaram um maior comprometimento da fala, foi utilizado o recurso da filmagem visando maior facilidade do registro e compreensão dos dados devido aos distúrbios de linguagem, podendo-se assim considerar outras formas de comunicação além da fala, como gestos, olhares, uso de sistemas de Comunicação Alternativa, entre outros. Para aquisição desse tipo de respostas, a pesquisadora disponibilizou para a criança, além dos recursos já utilizados por ela, uma prancha de comunicação temática com símbolos do PCS (abordando situações possíveis de respostas às perguntas da entrevista), um alfabeto e um bloco de notas, caso fosse necessária a criação de novos símbolos durante a entrevista.

Para facilitar a compreensão dos participantes em relação ao termo Tecnologia Assistiva foi esclarecido, antes da entrevista, que o termo referia-se a qualquer tipo de adaptação ou modificação do material, da tarefa ou do mobiliário utilizados em sala de aula. Os cinco participantes responderam a todos os itens da entrevista.

\subsubsection{AnÁlise dos DADOS}

As entrevistas com as crianças, três filmagens e dois áudios foram transcritas na íntegra. Posteriormente, as filmagens e áudios foram enviados a três juízes, todos mestres em educação especial com experiência profissional com criança com paralisia cerebral, há pelo menos dois anos, juntamente com uma carta de apresentação do trabalho e o roteiro de perguntas utilizado pela pesquisadora. Os juízes foram convidados a transcrever a entrevista na íntegra, sendo esta transcrição posteriormente comparada às transcrições feitas pela pesquisadora.

Foi realizado o cálculo de concordância em registros de eventos e duração, descrito por Fagundes (1985), utilizando-se os dados das transcrições apresentados pelos juízes e pesquisadora. Segundo o autor, quando os índices de concordância mostram-se acima de $70 \%$ pode-se considerar que: os registros são confiáveis, as categorias empregadas foram bem definidas, os comportamentos estão sendo identificados sem muita dificuldade e que os observadores encontramse suficientemente treinados. Neste estudo, foi utilizado o índice de concordância total da entrevista. Os índices obtidos nas cinco entrevistas variaram de 80 a $95 \%$, podendo ser considerados um índices de concordância elevado, sendo todas as transcrições das entrevistas consideradas válidas para a análise.

Os dados obtidos através das entrevistas com as crianças foram analisados na íntegra, optando-se em realizar uma categorização de acordo com os temas da entrevista. A seguir serão apresentados os resultados e discussão do estudo. 


\section{Resultados e discussão}

Apresentam-se os resultados e discussões de parte dos principais achados do estudo que serão sistematizados de acordo com os temas abordados na entrevista: a) Identificação dos recursos de Tecnologia Assistiva pelas crianças, b) A utilização dos recursos de Tecnologia Assistiva para a realização das tarefas, c) O processo de implementação dos recursos de Tecnologia Assistiva, d) A Tecnologia Assistiva e a comunicação e e) A Tecnologia Assistiva e o processo de escolarização.

\subsection{IdentificaÇão dos recursos de TeCnOlogia Assistiva utilizados Pelas Crianças}

Tem minha cadeira... caderno , o lápis que tem um coisa branca. (C1)

A adaptação que eu uso é a adaptação de xérox. (C2)

A pulseira. (C3)

As letrinhas e a mesa... é muito importante para mim. (C4)

Tem uma professora que ajuda e faz um material diferente. (C5)

Considerando-se os relatos das crianças, pode-se notar que elas descreveram como recursos de tecnologia assitiva os materiais adaptados, tarefas adaptadas, recursos humanos e mobiliário adaptado. Dessa forma, a tecnologia pode ser vista como recursos amplos, assim como o descrito pelo Comitê de Ajudas Técnicas, que a define como um campo amplo de serviços, estratégias, equipamentos e práticas que visam facilitar e ampliar melhorias para os problemas apresentados por indivíduos com deficiências.

Alguns recursos, embora fossem utilizados pelas crianças, não foram citados por elas, como é o exemplo da escriba feita pela mãe em sala de aula, uso de tesoura adaptada e molde vazado, as tarefas adaptadas e a escriba feita pelos colegas, e a prancha de comunicação. Pode-se hipotetizar que as crianças relataram os recursos que consideraram recursos de Tecnologia Assistiva; ou descreveram apenas os que usam usavam com maior frequência; ou os que eram são mais importantes para elas.

\subsection{UtilizaÇão dos recursos de TeCnOlogia Assistiva para a Realização de tarefas}

Em relação ao auxílio trazido pelo recurso de Tecnologia Assistiva, as crianças relacionaram esse auxílio à produção e à funcionalidade como, por exemplo, escrever, fazer lição, rabiscar.

Quatro alunos relataram que o recurso de Tecnologia Assistiva auxilia a fazer a lição, a escrever, a rabiscar, a fazer a tarefa sozinho, estar na escola e aprender. Uma criança referiu que não auxilia porque é difícil de usar.

Ajuda. De fazer lição. (C1)

Olha para ser sincero, eu acho que assim, eu como meu caso eu precisaria de uma escrita maior para que eu pudesse estudar. (...) Esses recursos me ajudam demais e se não fosse esses recursos eu estaria fora da escola. Eles me ajudam a aprender, me ajuda tipo ser uma pessoa quase normal tirando minha deficiência. (C2) 
Ajuda a escrever. (C3)

Ajuda. Eu faço sozinho com o lápis. (C4)

Não ajuda porque é difícil de usar. (C5)

Considerando-se que as crianças do nível motor IV e V apresentam maiores limitações à participação e à funcionalidade, como apontado pela literatura (MANCINI et al., 2004; BECKUNG; HAGBERG, 2002; SILVA et al., 2004), pode-se refletir sobre a importância dada por esses alunos à execução das tarefas e sobre os pontos positivos que as mesmas trazem a eles. Nota-se também a necessidade de criar estratégias que possibilitem a participação do aluno mais comprometido motoramente nas atividades produtivas da escola.

Os alunos que referiram a necessidade de outros recursos de Tecnologia Assistiva apontaram para os que auxiliam à escrita e ao uso do computador ou a máquina copiadora dentro da sala de aula.

O que o eu mais necessitaria no momento é o computador ou ter uma máquina de xérox dentro da classe porque eu tendo a máquina lá eu copiaria a tarefa e digitaria no computador. Eu precisaria mais disso. (C2)

Esse relato pode indicar demandas importantes que devem ser consideradas na situação da escolarização desses alunos, como por exemplo, que os recursos devem estar disponíveis dentro de sala de aula para que o aluno possa fazer uso dos mesmos de acordo com suas necessidades, para responder e acompanhar às diferentes dinâmicas e atividades que ocorrem durante as aulas.

Browning (2002) destacou que a participação da criança em atividades de leitura e escrita desenvolve o pensamento e o aprendizado de forma geral. Para que o mesmo ocorra com o aluno com deficiência física, a autora refere que o aluno deve apropriar-se do meio em que está inserido participando de um ambiente que ofereça variabilidade no acesso aos materiais pedagógicos. Dessa forma, serão oferecidas maiores oportunidades de participação ativa ampliando as possibilidades de execução de tarefas com autonomia.

No presente estudo, nota-se a necessidade de disponibilizar ao aluno um conjunto variado de recursos de Tecnologia Assistiva que possa auxiliá-lo na execução de diferentes atividades, tanto no ambiente de sala de aula como em outros dos quais a criança participa.

\subsection{A implementação dos recursos de Tecnologia Assistiva}

Outro aspecto importante trazido pela literatura é a participação do usuário de tecnologia no processo de escolha e implementação do recurso, a realização de treinamento para o bom desempenho do usuário e adesão ao recurso (SCHERER et al., 2005; RIEMER-REISS; WACKER, 2000; COPLEY; ZIVIANI, 2004). Hipotetiza-se que esse fator possa influenciar negativamente na motivação, 
empenho do usuário e, consequentemente, fazer com que o recurso torne-se descontextualizado e perca seu propósito.

Nenhuma criança participou da escolha de seu recurso de Tecnologia Assistiva. Três alunos não realizaram treino com o recurso antes de usá-lo na escola e duas crianças referiram ter treinado uma com o pai e a outra com a professora.

Não (participou da escolha). (C1)

Não (participou), o N. (terapeuta ocupacional) é quem ajudou. (C3)

Já veio daquele jeito. (C4)

Não (treinei) já usei direto. A professora me deu o lápis com o negócio. (C1)

A necessidade de manutenção do recurso de Tecnologia Assistiva também foi citada por um aluno como uma interferência negativa.

Olha, ajuda um pouco e atrapalha um pouco. Ajuda aprender e tal, mas às vezes a máquina de xérox está quebrada ai atrasa sabe é um pouquinho embaçado. (C2)

Segundo Scherer et al. (2005), a manutenção pode ser também um fator que influencia no desejo ou habilidade de uma pessoa em usar recursos de Tecnologia Assistiva. Por isso, deve-se pensar em outras estratégias ou disponibilizar diferentes recursos ao aluno, para que durante o período de manutenção haja outras possibilidades e não haja desmotivação e prejuízos à participação do aluno.

\subsection{A Tecnologia Assistiva e a comunicação}

Três alunos referiram que o professor os compreende e dois relataram que compreende parcialmente. Quando isso ocorre, os alunos procuram ajuda dos colegas para auxiliar a professora na compreensão.

Tem coisa que ela (professora) entende e outra que não. Quando ela não entende eu chamo minha amiga. (C1)

Entende um pouco, quando a professora não entende eu falo para os meus amigos. (C4) Sim. (C5)

Quatro crianças referiram que os colegas as compreendem. Uma disse que não há compreensão dos colegas nem com o uso da prancha de comunicação.

Entendem mas a professora não. (C1)

Não. Eles não entendem o que eu falo nem com a prancha. (C5)

A partir dessas colocações é possível discutir sobre as implicações trazidas pela dificuldade de comunicação. Pelosi (2003) pontuou que o aluno que possui habilidade de comunicação prejudicada também tem comprometida 
a expressão de seus sentimentos, de opiniões e preocupações, podendo interferir negativamente o seu desenvolvimento acadêmico e social.

Wolff (2001) ao pesquisar o contato com o outro através da Comunicação Alternativa, constatou que quando as crianças perceberam que o uso de prancha de Comunicação Alternativa gerava um efeito desejado, elas passavam a utilizá-la para ampliar sua linguagem. Porém, a autora pontua que há momentos em que a prancha não é necessária, que não substitui o que já funciona e ressalta que a mesma será utilizada quando a comunicação não oral não for suficiente.

Von Tetzchner et al. (2005) apresentaram alguns estudos sobre as atitudes de pares falantes com as crianças com dificuldades de comunicação. Os autores mostraram que crianças usuárias de Comunicação Alternativa raramente utilizavam seus sistemas ao interagir com seus pares. Na maioria das ocasiões, os pares falantes iniciavam os tópicos de conversação ou faziam as perguntas para que os usuários de sistemas de apoio respondessem. São raramente descritas estratégias em que se promovam o uso de Comunicação Alternativa do próprio colega no brincar e na conversação.

Nesse estudo, pode-se notar que as crianças com dificuldade de comunicação quando não compreendidas buscaram o auxílio dos colegas falantes da sala para auxiliarem na comunicação com seu professor, mostrando terem iniciativas comunicativas e perseverarem nas mesmas. A participação dos pares como colaboradores pareceu ser favorável ao contexto da comunicação em sala de aula, devendo-se considerar a importância de se levar os preceitos de uma cultura colaborativa ao cotidiano escolar.

Thomas, Korinek e McLaughlin (1999) abordaram a questão do apoio colaborativo nas escolas. Os autores referiram que estabelecer uma cultura colaborativa representa uma importante mudança no apoio à educação inclusiva. Quando desenvolvidas relações positivas e de atenção entre os alunos, aumenta-se a possibilidade de aprendizado, as oportunidades de interação, o enriquecimento de forças e interesses e auxilia os participantes a desenvolverem novas habilidades e aprimorarem as já existentes. Se os estudantes sentem-se mal acolhidos ou inseguros na escola, eles terão mais dificuldades em mudar comportamentos ou em beneficiarem-se da instrução acadêmica.

$\mathrm{Na}$ cultura colaborativa, todos os estudantes, mesmo aqueles com significante necessidade de suporte, estão envolvidos em algum tipo de assistência ao outro como parte do desenvolvimento do senso de eficácia e responsabilidade.

\subsection{A Tecnologia Assistiva e o processo de escolarização}

As cinco crianças deste estudo referiram participar de todas as tarefas de sala de aula. Dentre elas são citadas matérias como matemática, trabalho coletivo, cópia e escrever. Quatro alunos descreveram-se com qualidades positivas como bonito, quieto, legal, igual a todos, vou ser modelo. Uma mostra-se estar triste. 
Eu faço matéria, matemática que é continha, copio umas coisas assim que a tia dá, a tia dá bastante lição. (C1)

Faço trabalho coletivo, trabalho em grupo, assim esse tipo de coisa né. (C2)

Faço. (faz o gesto de escrever). (C3)

Assim, eu ah sou uma pessoa legal sabe, às vezes eu fico nervoso, eu sou igual a todos sabe, e eu gostaria muito de poder ir mais longe, mais não tenho recurso suficiente. (C2)

Eu acho eu bonito. (C3)

Quando eu crescer eu vou ser modelo. (C4)

Me sinto triste por causa da escola. Não quis responder mais. (C5)

Pape, Kim e Weiner (2002) referiram que fatores sociais como o estigma podem ser trazidos pelo recurso de Tecnologia Assistiva, impactando negativamente o usuário ao atrair uma atenção não desejada. As crianças desse estudo referiram participar de todas as tarefas de sala de aula, mesmo que fossem adaptadas ou realizadas com uso de algum recurso de Tecnologia Assistiva. Tem-se como hipótese, que elas não se viram diferenciadas em relação às tarefas realizadas em sala de aula e pareceram não ver nos recursos de Tecnologia Assistiva uma fonte de estigma.

Porém, os relatos também podem levar à reflexão sobre a utilização de recursos de tecnologia e às políticas de inclusão escolar. Como apontam Rocha, Castiglioni e Vieira (2005), a utilização dos recursos deve ser discutida em relação à qualidade de inclusão que promove e para isso deve estar contextualizada em discussões sobre as individualidades, cidadania, políticas e satisfação do cliente.

Outro aspecto relacionado à Tecnologia Assistiva foi o relato sobre a necessidade de adaptações ambientais. Um aluno desta pesquisa referiu a necessidade de adaptações no banheiro, pois utiliza fraldas e não há quem o auxilie nessa tarefa.

Eu quero falar do banheiro que é um problema porque não tem nenhum voluntário para me levar, eu tenho que vir de fralda para escola porque infelizmente não tem pessoa para me levar e muitas vezes é ruim porque na frente dos meus amigos...é muito ruim. Agora assim, eu queria fazer uma reivindicação porque é o seguinte. Eu acho que nós deficientes somos iguais a qualquer um, a qualquer um, qualquer pessoa, nós só temos limitações. (C2)

O estudo realizado por Silva et al. (2004), juntamente com os achado do presente estudo, reforçam a necessidade de estudos e práticas em relação aos ambientes escolares. Os autores mostraram que o grau de comprometimento motor é apresentado como indicativo para o nível de participação de atividades funcionais em seis ambientes da escola regular (sala, banheiro, recreio, lanche, transporte e transições). Porém, fatores como autonomia e acessibilidade estão diretamente relacionados já que apenas o uso de recurso adaptado não garante a autonomia se o direito de acessibilidade não for efetivado. 
Para que haja eficácia no uso de recursos de Tecnologia Assistiva, o modelo de Matching Person and Technology (MPT) trazido por Scherer et al. (2005) sugeriu a avaliação de três áreas: os fatores psicossociais, ambientais e os associados ao recurso. Neste estudo, pode-se observar a importância da associação desses três fatores.

Muitos relatos mostraram a persistência das crianças em relação ao uso dos recursos que disponibilizam, porém, muitas vezes, as características do próprio recurso ou do contexto podem levá-los a desmotivação.

\begin{abstract}
Às vezes é o que eu falei eu não tenho um recurso suficiente para eu poder ir até onde eu quiser, tem sempre uma barreira entendeu, nunca, nunca... dou dois passinhos tem outra barreira dou outro passinho tem outra barreira. Assim, é quando tem um recurso aparece uma barreira ai consigo outro recurso tem outra barreira. (C2)
\end{abstract}

\title{
4 Conclusão
}

O presente estudo apresentou a percepção das crianças usuárias de tecnologia no contexto da escola regular. Considerando que o mesmo dá voz às crianças com deficiência física, usuárias diretas dos recursos de Tecnologia Assistiva, este pode ser considerado um dos estudos pioneiros no âmbito nacional sob esta perspectiva.

Pode-se observar que as percepções das crianças foram relevantes e que elas mostraram-se capazes de apontar demandas e identificar quando e como os recursos podem ser limitantes dentro do contexto. Assim, aponta-se que a opinião das crianças deve ser considerada para que haja maior qualidade na inclusão escolar do aluno que necessita de recursos adaptados. Além disso, considerar as opiniões e a participação da criança na identificação de recursos de tecnologia contribuirá na compreensão do impacto, das demandas e das possíveis contribuições no processo de implementação e utilização do recurso de Tecnologia Assistiva

Pode-se perceber que embora a gravidade motora fosse um critério de inclusão deste estudo, todos os participantes foram capazes de expressar respostas coerentes e esclarecedoras ao tema que foi investigado. Assim, observa-se que os relatos trazidos pelas crianças devam ser valorizados já que, neste estudo, mostraram-se de grande relevância à investigação sobre o uso dos recursos assistivos. Mais pesquisas na área de tecnologia devem envolver a opinião do usuário e este estudo confirma que a opinião da criança usuária deve ser contemplada.

De maneira geral, as crianças do estudo descreveram como recursos de Tecnologia Assistiva os materiais adaptados, tarefas adaptadas, recursos humanos e mobiliário adaptado. Elas consideraram que seus recursos de Tecnologia Assistiva auxiliaram a execução de tarefas e a participação nas atividades em classe comum. Em relação ao processo de implementação do recurso, as crianças relataram que 
não tiveram nenhuma participação no processo de escolha e que apenas algumas delas receberam treinamento.

Através das entrevistas realizadas com os participantes, observou-se que os recursos de Tecnologia Assistiva já estão inseridos na escola regular, porém parecem estar sendo implementados sem sistematização, acompanhamentos sistemáticos e/ou parcerias.

Aponta-se que novos estudos sobre os efeitos da Tecnologia Assistiva na escolarização da criança com deficiência física devam ser realizados no Brasil. Não obstante, os resultados aqui apresentados evidenciam que os recursos de Tecnologia Assistiva trouxeram contribuições ao processo de escolarização da criança com paralisia cerebral em classe de ensino fundamental comum. Alguns desafios ainda permeiam esse contexto como a ausência do trabalho colaborativo, a prática das políticas de inclusão e a falta de sistematização na implementação dos recursos de Tecnologia Assistiva.

Este estudo realizou a investigação do cotidiano escolar do aluno com paralisia cerebral usuário de Tecnologia Assistiva, através da apresentação de situações vivenciadas em sala de aula. Observa-se que a escolha pelas situações de sala de aula foi enfatizada por considerar-se que o aluno despende a maior parte do período escolar engajado em atividades produtivas e de comunicação.

Considera-se que o estudo respondeu aos objetivos propostos e pode contribuir para o conhecimento que vem sendo produzido na área, destacando-se a realidade brasileira. Além disso, o estudo pode fornecer elementos para reflexões acerca da inclusão escolar do aluno com deficiência física mais comprometido motoramente e sobre o papel da Tecnologia Assistiva na escola.

\section{REFERÊNCIAS}

ALPINO, A. M. S. O aluno com paralisia cerebral no ensino regular: ator ou expectador do processo educacional? 2003. 141f. Dissertação (Mestrado em Educação do Indivíduo Especial) - Centro de Educação e Ciências Humanas, Universidade Federal de São Carlos, São Carlos, 2003.

BECKUNG, E.; HAGBERG, G. Neuroimpairments, activity limitations and participation restrictions in children with cerebral palsy. Developmental Medicine \& Child Neurology, v.44, p. 309-316, 2002.

BERSCH, R.C.R.; PELOSI, M. B. Portal de ajudas técnicas para a educação: equipamento e material pedagógico para a educação, capacitação e recreação da pessoa com deficiência física: tecnologia assistiva: recursos de acessibilidade ao computador. Brasília: Secretaria de Educação Especial, 2007. 
BRASIL. Ministério da Educação e Cultura. Portal de ajudas técnicas para educação: equipamento e material pedagógico para educação, capacitação e recreação da pessoa com deficiência física: recursos pedagógicos adaptados. Brasília: MEC, Secretaria de Educação Especial, 2002. Disponível em: <http:// portal.mec.gov.br/seesp/index.php?o ption=content\&task=view\&id=157\&Itemid=309>. Acesso em: 19 jul. 2010.

. Ministério da Educação e Cultura. Números da Educação Especial no Brasil. Brasília: MEC Secretaria de Educação Especial, 2006. Disponível em: <http:// portal.mec. gov.br/seesp/index.php?option=content\&task=view\&id=62\&Itemid=191>. Acesso em: 23 ago. 2009.

Subsecretaria Nacional de Promoção dos direitos da pessoa com deficiência CORDE. Comitê de ajudas técnicas, 2007. Disponível em: <http:/ / portal.mj.gov.br/ corde>. Acesso em: 29 set. 2010.

Ministério da Educação e Cultura. Resumo técnico - Censo Escolar 2010. Brasília: MEC, Secretaria de Educação Especial, 2011. Disponível em: <http:/ / portal.mec.gov.br/ index.php?option=com_content\&view=article\&id=16179>. Acesso em: 18 jun. 2011.

BROWNING, N. O desenvolvimento das aptidões literárias da criança com deficiência física. Temas sobre desenvolvimento, São Paulo, v.11, n.64, p.35-41, 2002.

COPLEY, J.; ZIVIANI, J. Barriers to the use of assistive technology for children with multiple disabilities. Occupational Therapy International, v.11, n.4, p.229-43, 2004.

COSTER et al. School Function Assesment: user manual. Texas: Therapy Skill Builders, 1998.

FAGUNDES, A.J.F.M. Descrição, definição e registros de comportamento. São Paulo: Ed. Edicon, 1985.

GIANNI, M.A. Paralisia cerebral. Terapia ocupacional na reabilitação física. São Paulo: Roca, 2003.

GODÓI, A. M.; GALASSO, R.; MIOSSO, S.M.P. Educação infantil: saberes e práticas da inclusão- dificuldades de comunicação e sinalização - deficiência física. Brasília: MEC, Secretaria de Educação Especial, 2002. Disponível em: <http:// portal.mec.gov.br/seesp/ index.php?option=content\&task=view\&id=87\&Itemid=216> Acesso em: 06 jul. 2010.

HEMMINGSSON, H.; LIDSTROM, H.; NYGARD, L. Use of assistive technology devices in mainstrain schools: student's perspective. American Journal of Occupational Therapy, v.63, n.4, p. 463-472, 2009.

HIRATUKA, E.; MATSUKURA, T.S. Sistema de classificação da função motora grossa para paralisia cerebral (GMFCS). 2007. Disponível em: <http:/ / motorgrowth.canchild. ca/en/GMFCS/resources/GMFCS_portuguese.pdf>. Acesso em: 27 jul. 2011.

HUANG, I.; SUGDEN, D.; BEVERIDGE, S. Children's perceptions of their use of assistive devices in home and school settings. Disability and Rehabilitation Assistive Technology, v.4, n.2, p. 95-105, 2009.

KRÄGELOH-MANN I, et al. Bilateral spastic cerebral palsy - a comparative study between south-west Germany and western Sweden. I: Clinical patterns and disabilities. Developmental Medicine \& Child Neurology, v.35, p.1037-1047, 1993. 
LOVARINI, M.; MCCLUSKEY, A.; CURTIN, M. Editorial: Critically Appraised Papers Limited high-quality research on the effectiveness of assistive technology. Australian Occupational Therapy Journal, v.50, p.53, 2006.

MANCINI, M. C. et al. Gravidade da paralisia cerebral e desempenho funcional. Revista brasileira de fisioterapia, São Carlos, v.8, n.3, p. 253-260, 2004.

MANZINI, E. J. ; DELIBERATO D. Portal de ajudas técnicas para educação : equipamento e material pedagógico especial para educação, capacitação e recreação da pessoa com deficiência física : recursos para Comunicação Alternativa. MEC: Secretaria de Educação Especial, Brasília, 2006. Disponível em: <http:// portal.mec.gov.br/seesp/index.php?opti on $=$ content\&task=view\&id=157\&Itemid=309. $>$ Acesso em: 29 set. 2010.

MARTURANO, E. M. Fatores de risco e proteção no desenvolvimento sócio-emocional de crianças com dificuldade de aprendizagem. Temas em educação especial avanços recentes. São Carlos: Ed. Edusfcar, 2004.

OSTENSJO, S.; CARLBERG, E. B.; VOLLESTAD, N. K. The use and impact of assistive devices and other environmental modifications on everyday activities and care in young children with cerebral palsy. Disability and Rehabilitation, v. 27, n. 14, p. 849- 861, 2005.

PALISANO, R. et al. Development and reliability of a system to classify gross motor in children with cerebral palsy. Development Medical Child Neurologic, v.39, p.214-223, 1997.

PAPE, T.L.B.; KIM, J; WEINER, B. The shaping of individual meanings assigned to assistive technology: a review of personal factors. Disability and Rehabilitation, v.24, n.1/2/3, p.5-20, 2002.

PELOSI, M.B. A comunicação alternativa escrita. In: NUNES, L.R.O.P. (Org.). Favorecendo o desenvolvimento da comunicação em crianças e jovens com necessidades educacionais especiais. Rio de Janeiro: Dunya, 2003. p.203-216

RIEMER-REISS, M. L.; WACKER, R.R. Factors associated with assistive technology discontinuance among individuals with disabilities. Journal of Rehabilitation. v.66, n.3, p.44-50, 2000.

ROCHA, E.F.; CASTIGLIONI, M.C.; VIEIRA, R.C. A inclusão da criança com deficiência na escola comum: reflexões sobre o papel da terapia ocupacional. Revista de Terapia Ocupacional da Universidade de São Paulo, v.12, n1/3, p.8-14, 2001.

ROTTA, N.T. Paralisia cerebral, novas perspectivas terapêuticas. Jornal de Pediatria, Rio de Janeiro, v.78, Supl.1, 2002.

SCHERER, M. J. et al. Predictors of assistive technology use: The importance of personal and psychosocial factors. Disability and Rehabilitation, v.27, n. 21, p.1321-1331, 2005.

SCHINEMER et al. Atendimento educacional especializado - deficiência física. Brasília: Secretaria de Educação Especial, 2007.

SILVA, A. F.; CASTRO, A. L.; BRANCO, M. C. A inclusão escolar de alunos com necessidades educacionais especiais- deficiência Física. Brasília: Secretaria de Educação Especial, 2006.

SILVA, A. I. T. et al. Perfil funcional de crianças com paralisia cerebral na escola regular segundo tipo de escola e comprometimento motor. Temas sobre desenvolvimento, São Paulo, v.13, n.74, p. 5-13, 2004. 
ALVES, A. C. J.; MATSUKURA, T. S.

THOMAS, C.W.; KORINEK, L; MCLAUGHLIN, V.L. Collaboration to support students success. Focus on Exceptional Children, v.32, n.3, p.1-18, 1999.

VON TETZCHNER, S. et al. Inclusão de crianças em educação pré-escolar regular utilizando comunicação suplementar e alternativa Revista Brasileira de Educação Especial. Marília, v.11, n. 2, 2005.

WOLFF, L. M. G. Comunicação suplementar e/ou alternativa nos transtornos invasivos do desenvolvimento. 2001. Dissertação - Pontifícia Universidade Católica de São Paulo, São Paulo, 2001.

Recebido em: 10/11/2010

Reformulado em: 30/06/2011

Aprovado em: 05/07/2011 